\title{
Diamond Films on Stainless Steel Substrates with an Interlayer Applied by Laser Cladding
}

\author{
Andre Contin ${ }^{a}$, Kenya Aparecida Alves ${ }^{a}$, Raonei Alves Campos ${ }^{b}$, Getúlio de Vasconcelos ${ }^{c}$, Djoille \\ Denner Damm ${ }^{a}$,Vladimir Jesus Trava-Airoldi ${ }^{a}$ Evaldo José Corat ${ }^{a}$ \\ ${ }^{a}$ Laboratório Associado de Sensores e Materiais - LAS, Instituto Nacional de Pesquisas Espaciais - \\ INPE, São José dos Campos, SP, Brazil \\ ${ }^{b}$ Federal University of South and Southeast of Pará - UNIFESSPA, Marabá, PA, Brazil \\ ${ }^{c}$ Laboratório de Desenvolvimento de Aplicações de Lasers e Óptica - DedALO, Instituto de Estudos \\ Avançados - IEAv, São José dos Campos, SP, Brazil
}

Received: May 3, 2016; Revised: January 3, 2017; Accepted: February 6, 2017

\begin{abstract}
The objective of this work is the Hot Filament Chemical Vapor Deposition (HFCVD) of diamond films on stainless steel substrates using a new technique for intermediate barrier forming, made by laser cladding process. In this technique, a powder layer is irradiated by a laser beam to melt the powder layer and the substrate surface layer to create the interlayer. The control of the laser beam parameters allows creating homogeneous coating layers, in rather large area in few seconds. In this work, the silicon carbide powder $(\mathrm{SiC})$ was used to create an intermediate layer. Before the diamond growth, the samples were subjected to the seeding process with diamond powder. The diamond deposition was performed using Hot-Filament CVD reactor and the characterizations were Scanning Electron Microscopy, X-ray diffraction, Raman Scattering Spectroscopy and Scratch Test.
\end{abstract}

Keywords: Laser Cladding, HFCVD, Diamond Film

\section{Introduction}

CVD diamond films on steel substrates present great interest because of their unique properties. CVD diamond film as a protective film produces an increase in surface hardness, thermal conductivity; on the other hand, it decreases low friction coefficient. Steel is widely applied in the industry. Diamond coating on steel may provide many applications because of diamond intrinsic properties. On the other hand, there are still difficulties at adhesion between diamond films and steel substrates.

Direct synthesis of diamond film on steel has been limited because of at least three major obstacles ${ }^{1,2}$. First iron is not a catalyst for CVD diamond growth, which forms graphite layer on the surface instead of a diamond. Second, the carbon from the gas phase has high diffusion rate into the steel at CVD temperatures, decreasing diamond nucleation. Third, the AISI 304L has a higher thermal expansion coefficient $\left(17.3 \times 10^{-6} \mathrm{~K}^{-1}\right)$ than the diamond $\left(0.8 \times 10^{-6} \mathrm{~K}^{-1}\right)$ resulting in a mismatch, this fact increases the residual stresses in a film-substrate interface, leading to a poor adhesion.

There are many alternatives described in literature to reduce these three issues, as the surface modifications ${ }^{3}$ and the deposition of intermediate layers ${ }^{4,5}$ to block the iron diffusion to the substrate surface and the carbon diffusion from the gas phase into the steel, during the CVD diamond deposition, as well to reduce residual stresses effect between the diamond and the steel.

*e-mail: andrecontin@yahoo.com.br
The literature shows interlayers to achieve adherent diamond films on steel substrates, such as $\mathrm{Si}^{6}, \mathrm{CrN}^{7}, \mathrm{TiC}^{8}$. Lin et al. ${ }^{9}$ obtained good adhesion on steel by electroplated $\mathrm{Ni}$ interlayer. Fan et al. ${ }^{10}$ reported adherent diamond coating on steel with a titanium interlayer by DC sputtering, pull-off tests revealed the diamond coating adhesion was better than $13 \mathrm{~N} / \mathrm{mm}^{2}$. Buijnsters et al. ${ }^{11}$ showed that $\mathrm{CrN}$ interlayer, by arc PVD, was efficient to deposit diamond film onto highspeed steel substrate; on the other hand, $\mathrm{CrN}$ intermediate barrier didn't provide a uniform diamond deposition for the 316 stainless steel.

This study explores the use of $\mathrm{SiC}$ interlayer for diamond deposition by laser cladding process. The barrier creation by laser cladding process is innovative. Process objective ${ }^{12}$ is the deposition of a molten layer on the substrate surface. The process uses power laser beam to melts the powder on the surface, forming an adherent coating to the substrate ${ }^{13}$.

\section{Experimental}

The substrates for diamond coating were AISI 304L steel disks with of $25.4 \mathrm{~mm} \times 3 \mathrm{~mm}$ (diameter x thickness). The radiation source for laser cladding was a carbon dioxide laser (Synrad - SH) with the output power of $50 \mathrm{~W}$ and beam diameter of $300 \mu \mathrm{m}$. The beam intensity was $70 \mathrm{~kW} / \mathrm{cm}^{2}$. The SiC powder was commercially available silicon carbide powder (Treibacher Schleifmittel Brasil). SiC average grain size was $4 \mu \mathrm{m}$ in all experiments

Table 1 shows the parameters used in the laser to create $\mathrm{SiC}$ intermediate layer on steel. 
Table 1. Laser cladding parameters.

\begin{tabular}{lccc}
\hline Laser Parameters & 1-SiC layer & 2-SiC layer & 3-SiC layer \\
\hline Resolution (dots per square inch) & 600 & 600 & 600 \\
Number of heating cycles & 2 & 2 & 2 \\
Beam scanning speed (mm/s) & 50 & 100 & 100 \\
Atmosphere & $\mathrm{N}_{2}-51 /$ min flow & $\mathrm{N}_{2}-51 /$ min flow & $\mathrm{N}_{2}-51 /$ min flow \\
\hline
\end{tabular}

We employed two-step process in laser cladding. The first step consists of powder application by air gun, followed by laser incidence (second step). For 3-layer $\mathrm{SiC}$, both the powder pulverization and laser irradiation were repeated 3 times, respectively.

Before CVD diamond deposition process, we introduced the seeding process that introduces diamond seeds as nuclei for the CVD diamond growth. The nucleation mechanism of diamond particles was based on ESA (Electrostatic SelfAssembly) process ${ }^{14}$. The first stage was sample immersion for 30 minutes in an aqueous solution with PDDA \{- Poly (diallyldimethylamonium chloride)\}. The last stage was immersion in a aqueous solution containing $4 \mathrm{~nm}$ dispersed diamond powders and the anionic polymer PSS - (Poly (sodium 4 - styrenesulfonate), for a period of $30 \mathrm{~min}^{15,16}$. After each stage, we washed the sample in DI water.

Diamond film deposition was performed in a HFCVD (Hot Filament Chemical Vapor Deposition) reactor. A set of 6 tungsten filaments with diameter of $125 \mu \mathrm{m}$, kept at a temperature of around $2200{ }^{\circ} \mathrm{C}$ was the activation region. The distance between the filaments and the sample was at $5 \mathrm{~mm}$. During the deposition, the substrate surface was $630{ }^{\circ} \mathrm{C}$ to lessen thermal stress induced by the difference in thermal expansion coefficients between diamond film and the substrate. To get a better anchoring of diamond film, we used TMCVD (Time Modulated Chemical Vapor Deposition) process ${ }^{17}$. This method consists of altering the methane concentration from low to high at predetermined times.

At the beginning of the diamond deposition process, samples were subjected for 20 minutes in a typical concentration of microcrystalline diamond (MCD), $2 \% \mathrm{CH}_{4}$ dissolved in hydrogen at a $100 \mathrm{sccm}$ total flow rate and 50 Torr constant pressure, to stabilize the process and the growth temperature. In the first modulation, the methane percentage was $6 \%$ dissolved in hydrogen for 15 minutes. The second modulation was after two hours of MCD typical concentration growth, with the same concentrations described in the first. The time deposition was $3 \mathrm{~h}$.

Scratch test (UMT, CETR) evaluated adhering silicon carbide layer on the substrate surface. X-ray Diffraction (Panalytical X'pert Pro) analyzed phase quantitative in the laser cladding process. Qualitative analysis was made by Scanning Electron Microscopy (JEOL JSM-5310), FEGSEM (Mira 3-Tescan) and SEM (Vega-Tescan). Raman Scattering Spectroscopy (Renishaw 2000) with an argon laser excitation ( $514.5 \mathrm{~nm}$ ) analyzed compressive residual stresses of diamond film. Rockwell Hardness Tester (Wilson J 3R) with the hardened steel ball of $1 / 8$ inch diameter evaluated diamond coating adhesion on steel.

\section{Results and discussion}

Figure 1 shows the X-ray diffractogram of AISI 304L substrate with the characteristic peaks of the austenite phase $^{18}$. The radiation wavelength is $1.5418740 \AA(\mathrm{Cu}-\mathrm{Ka})$.

This steel has a high chromium and lower carbon content, with a typical composition of $8 \% \mathrm{Ni}, 18 \% \mathrm{Cr}$, $0.05 \% \mathrm{C}, 0.6 \% \mathrm{Si}, 1 \% \mathrm{Mn}$ and the balanced being $\mathrm{Fe}^{19,20}$. The thermal expansion coefficient of austenitic steel is higher than diamond film. This difference results in the tendency to diamond film fragmentation. Diamond film coating is a prosperous method to change the wear resistance of steel surface and to make further functionality.

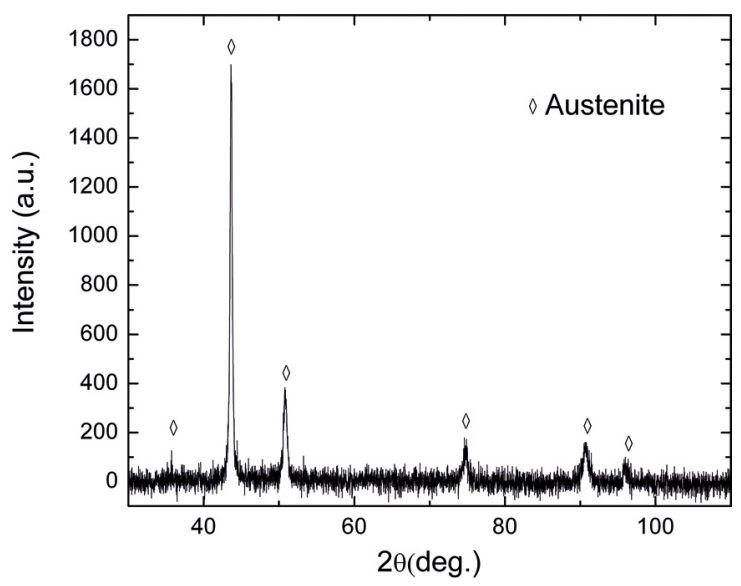

Figure 1. X-ray diffractogram of the AISI 304L sample.

Figure 2(a) shows the morphology of diamond film grown on bare steel. The time deposition was $3 \mathrm{~h}$ and surface temperature was $630^{\circ} \mathrm{C}$. It can be seen some diamond spherical particles on loose graphite soot. Some diamond nuclei coalesced and grew on the top of graphite soot, but they are under free-standing and can be removed easily. The figure 2(b) shows the characteristic Raman spectrum. In addition, the figure shows two bands centered at 1350 and $1590 \mathrm{~cm}^{-1}$. These bands correspond to the D-band and G-band of graphite ${ }^{21}$, respectively. 

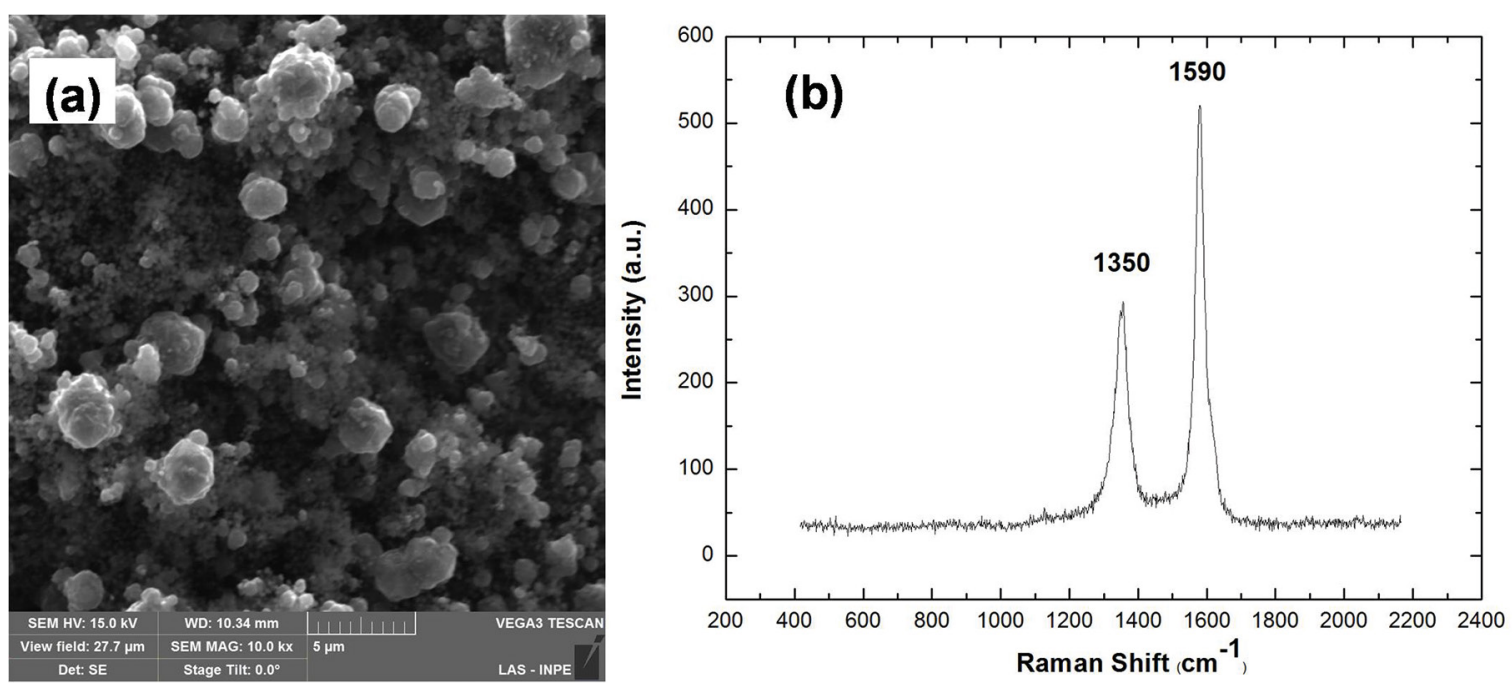

Figure 2. Diamond film on bare steel. (a) SEM image of diamond film on bare steel and (b) Raman spectrum of diamond film on bare steel.

Direct deposition of diamond film on bare steel leads to graphite soot creation due to iron catalytic effect in the graphite preferential nucleation. Intermediate layers are required to solve this problem.

Figure 3 shows the sample cross section after laser cladding process.

It can be noted the formation of a $\mathrm{SiC}$ intermediate layer with a granular structure on the steel substrate surface. The layer thickness was about 30 microns. During laser irradiation, a thin layer applied on the substrate generates total powder sublimation; on the other hand, a thick layer does not cause heat transfer, from the laser beam, to the substrate. It is important to note that three layers were fully sintered by laser incidence, thus it is not possible to distinguish them. In addition, the image does not show cracks in the coating. Figure 4 exhibits the interface elements mapping between the $\mathrm{SiC}$ layer and the substrate.

The elemental mapping technique provided a spatial distribution of the chemical elements present at the interface. The interface elements did not indicate a large diffusion

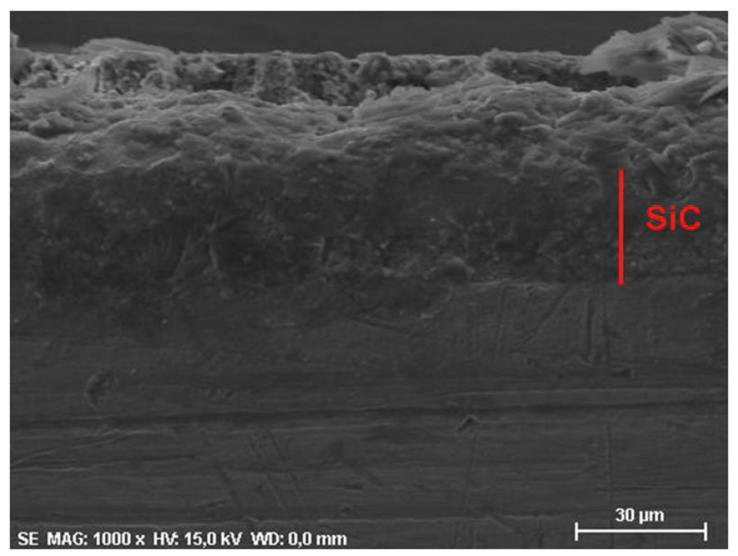

Figure 3. SEM image of AISI 304L cross section after laser cladding process.

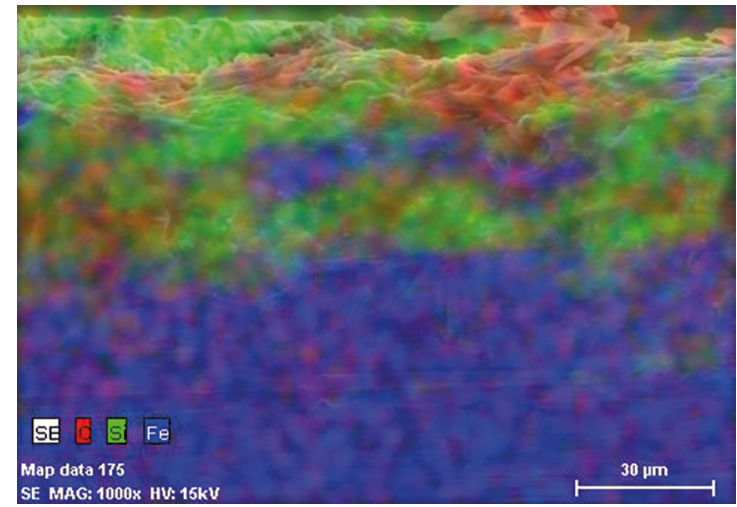

Figure 4. SEM image of the interface elemental mapping at interface.

between the $\mathrm{SiC}$ and AISI 304L (Fe) elements. The diffusion rate at the interface depends on the laser energy density ${ }^{22}$. Although the higher migration of iron atoms into the $\mathrm{SiC}$ interlayer decreases the barrier effectiveness, there is a need to create a diffusion pair ( $\mathrm{SiC}$ and $\mathrm{Fe}$ elements) in order to form a metallurgical bond.

Figure 5 attests scratch test.

The scratch test evaluated the adhesion between $\mathrm{SiC}$ interlayer and steel substrate. The value of normal force, at which the first failure of $\mathrm{SiC}$ interlayer is detected by photographic camera, was $41 \mathrm{~N}$. The intermediate layer must withstand the steel contraction during reactor cooling, in fact, behaving as a binding layer between the steel and the diamond. The high value of normal force can be related to strong metallurgical bond at a interface, formed during laser irradiation.

The surface roughness values of $\mathrm{SiC}$ intermediate layer were $\mathrm{Ra}=1.80 \mu \mathrm{m}, \mathrm{Rq}=2.61 \mu \mathrm{m}$ and $\mathrm{Rz}=6.77 \mu \mathrm{m}$. Laser incidence generates the sintering or semi-sintering of $\mathrm{SiC}$ grains. Then, the laser cladding forms intermediate barrier 


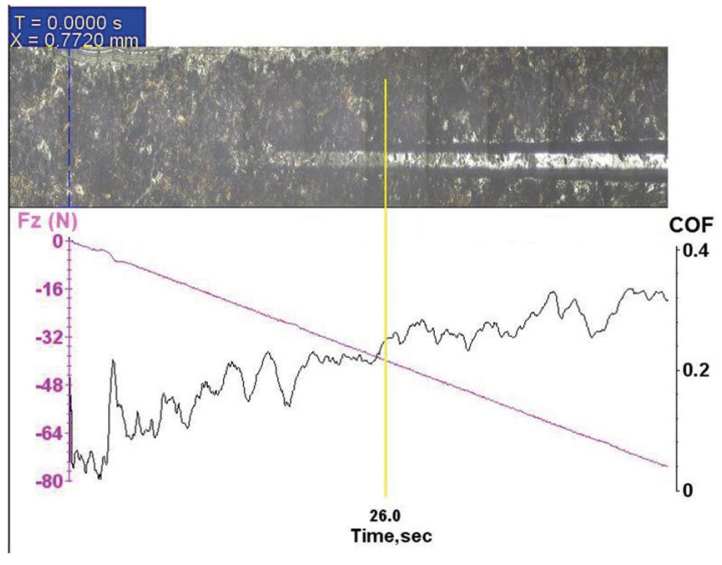

Figure 5. Graphical representation of the critical load (Fz) value.

with high surface roughness and, during the early diamond deposition stage, the diamond nuclei grow inside the $\mathrm{SiC}$ surface roughness, generating the interlocking action.

Figure 6 shows the morphology of diamond film grown on stainless steel.

The efficiency of diffusion process blocking is evidenced by the diamond growth. Diamond coating on SiC layer is uniform without spallation, the triple interlayer inhibited the carbon diffusion and thus, the substrate was not carburized. The film presents good nucleation, with uniform distribution, which presents granular structure, formed by grains coalescence. At higher magnification, letter (b), the image reveals clusters of diamond grains in nanometric scale ${ }^{23}$.

Figure 7 shows the characteristic Raman spectrum of the film grown on the AISI 304L substrate for $3 \mathrm{~h}$.

The Raman spectrum shows a peak centered at 1334 $\mathrm{cm}^{-1}$, a typical characteristic of the diamond structure, shifted of about $2 \mathrm{~cm}^{-1}$ from the diamond characteristic peak $\left(1332 \mathrm{~cm}^{-1}\right)$. It is correlated with residual stress in the diamond lattice ${ }^{24}$, which produces a compressive stress in the deposited diamond film.

The shoulders at $1140 \mathrm{~cm}^{-1}$ and $1490 \mathrm{~cm}^{-1}$ have been related to transpolyacetylene (TPA) presence at the grain boundaries, both of them are found in NCD films ${ }^{4}$. The spectrum shows the D-band of graphite $\left(1350 \mathrm{~cm}^{-1}\right)$, which appears because of $\mathrm{sp}^{2}$ disorder. Further, the Raman signal corresponding to $\mathrm{sp}^{2}$ amorphous carbon, so-called G-band of graphite, is observed near, at $1580 \mathrm{~cm}^{-1}$, its low intensity shows a high purity diamond film grown on steel $^{25}$. The NCD growth reduces residual stress in diamond films; which is an important fact since the higher stress leads to a diamond film delamination ${ }^{26}$.

The figure 8 shows the X-ray diffractogram after diamond growth.

From the diffractogram, it can be inferred that $\mathrm{SiC}$ phase is higher peak intensity after diamond growth. The appearance of diamond peak confirms the diamond deposition. The

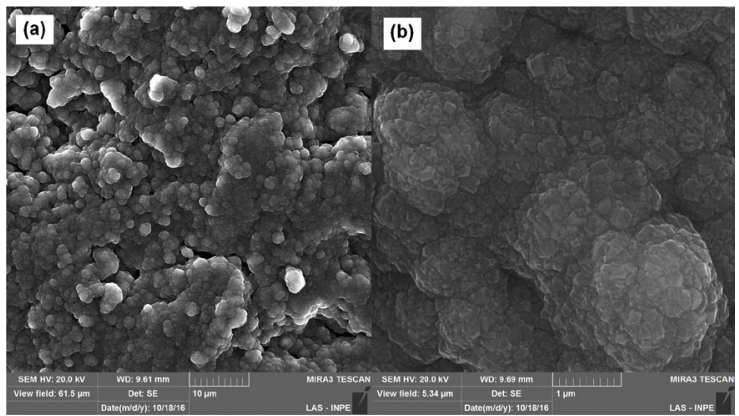

Figure 6. FEG-SEM image of diamond film on AISI 304L with $\mathrm{SiC}$ interlayer

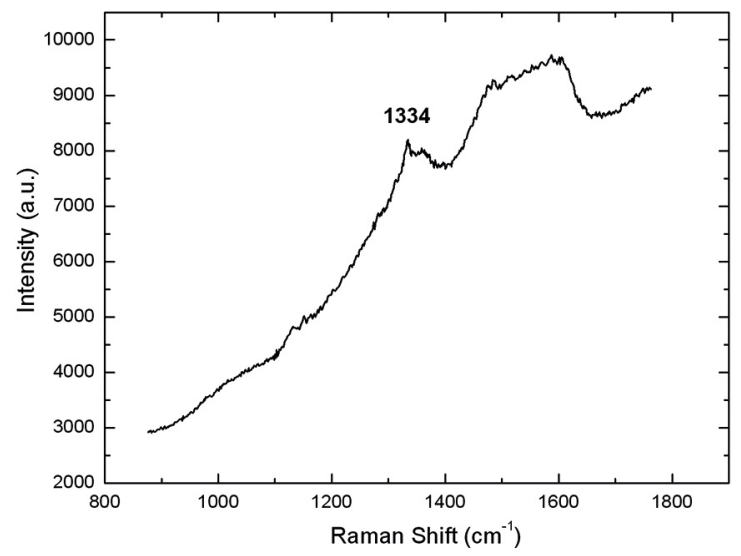

Figure 7. Raman spectrum of diamond film on AISI 304L with $\mathrm{SiC}$ interlayer.

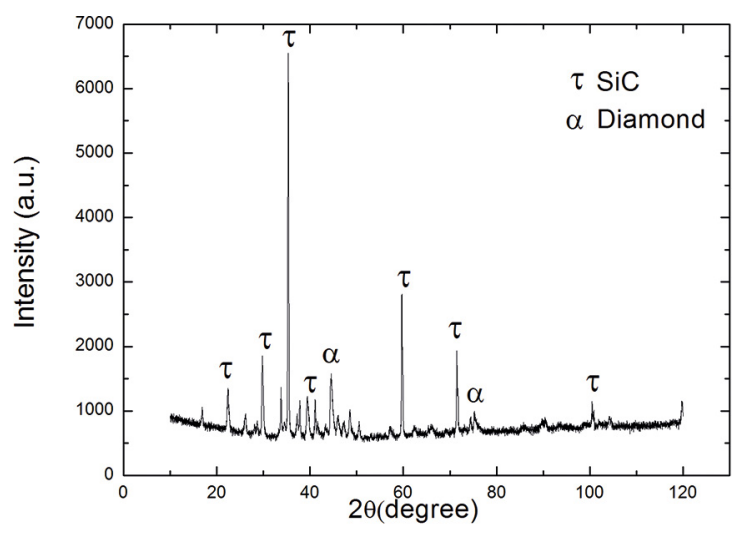

Figure 8. X-ray diffractogram of the diamond film on steel.

$\mathrm{SiC}$ intermediate barrier blocked the iron diffusion as no graphite peak is seen.

Figure 9 shows Rockwell indentation test on diamond film on steel.

The Figure 8 (a) and (b) show diamond coating after indentation at a load of 100 and $150 \mathrm{~kg}$, respectively. In both, there weren't delamination and cracking of diamond coatings around the prints. It is correlated with high diamond film adhesion 


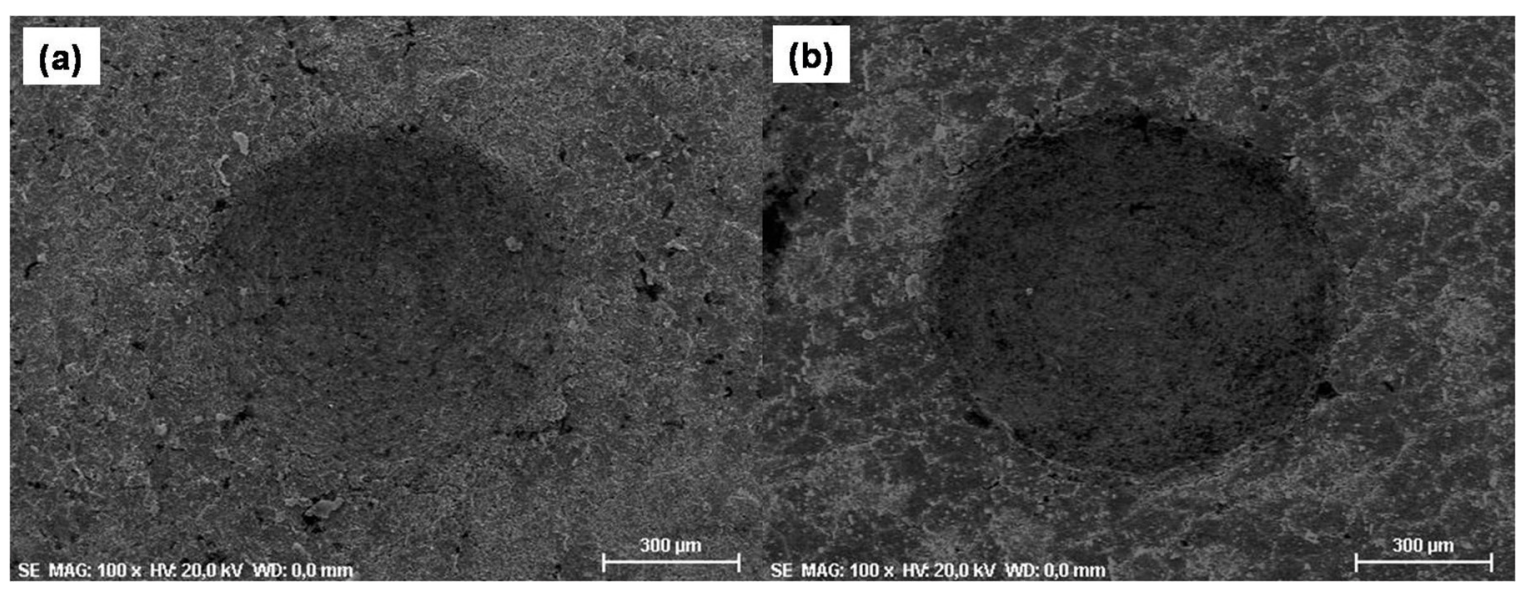

Figure 9. Rockwell indentation test of (a) $980 \mathrm{~N}$ (b) $1470 \mathrm{~N}$.

onto substrate ${ }^{4}$. In addition, the figure shows small concentric cracks around the print, compressive stress of diamond film inhibited radial cracks formation running in concentric $\mathrm{cracks}^{27}$.

From these results, it is possible to indicate that laser irradiation provided an excellent metallurgical bond with the substrate. In addition, SiC interlayer successfully suppressed the high carbon solubility into the bulk steel substrate and catalytic the effect of iron on graphite soot formation. In addition, $\mathrm{SiC}$ has thermal expansion coefficient intermediate between diamond and steel, which reduced the residual stress at an interface. Enhanced adhesion of the diamond film to the steel was guaranteed because of SiC interlayer. Laser cladding features a promising method to create the intermediate barrier for steel substrate. Additional experiments showed the SiC layer effectiveness as an intermediate barrier for diamond deposition.

\section{Conclusions}

In this work, adherent diamond films were deposited on AISI 304L substrate using an intermediate barrier, made by laser cladding. The interlayer blocked the iron diffusion to the substrate surface and carbon diffusion from the gas phase into the steel during the CVD diamond deposition. Further, the silicon carbide layer behaved as a binding layer, with intermediate mechanical and thermal properties between steel and diamond, this fact lessened the three main adherence problems between the diamond film and steel substrate.

\section{Acknowledgments}

The authors would like to thank FAPESP (Fundação de Amparo à Pesquisa do Estado de São Paulo) for financial support of this work.

\section{References}

1. Barei $\beta$ JC, Hackl G, Popovska N, Rosiwal SM, Singer RF. CVD diamond coating of steel on a CVD-TiBN interlayer. Surface and Coatings Technology. 2006;201(3-4):718-723.
2. Barei $\beta$ C, Perle M, Rosiwal SM, Singer RF. Diamond coating of steel at high temperatures in hot filament chemical vapour deposition (HFCVD) employing chromium interlayers. Diamond and Related Materials. 2006;15(4-8):754-760.

3. Tang W, Wang S, Lu F. Preparation and performance of diamond coatings on cemented carbide inserts with cobalt boride interlayers. Diamond and Related Materials. 2000;9(9-10):1744-1748.

4. Li YS, Tang Y, Yang Q, Xiao C, Hirose A. Diamond deposition on steel substrates with an $\mathrm{Al}$ interlayer. International Journal of Refractory Metals and Hard Materials. 2009;27(2):417-420.

5. Gowri M, Li H, Kacsich T, Schermer JJ, van Enckevort WJP, ter Meulen JJ. Critical parameters in hot filament chemical vapor deposition of diamond films on tool steel substrates with CrN interlayers. Surface and Coatings Technology. 2007;201(8):4601-4608.

6. Buijnsters JG, Shankar P, van Enckevort WJP, Schermer JJ, ter Meulen JJ. The applicability of ultra thin silicon films as interlayers for CVD diamond deposition on steels. Physica Status Solidi a. 2003;195(2):383-395.

7. Haubner R, Lux B. Diamond deposition on steel substrates using intermediate layers. International Journal of Refractory Metals and Hard Materials. 2006;24(5):380-386.

8. Polini R, Mattei G, Valle R, Casadei F. Raman spectroscopy characterization of diamond films on steel substrates with titanium carbide arc-plated interlayer. Thin Solid Films. 2006;515(3):1011-1016.

9. Lin CR, Kuo CT. High adhesion and quality diamond films on steel substrate. Diamond and Related Materials. 1998;7(6):903-907.

10. Fan QH, Fernandes A, Gracio J. Diamond coating on steel with a titanium interlayer. Diamond and Related Materials. 1998;7(2-5):603-606.

11. Buijnsters JG, Shankar P, Fleischer W, van Enckevort WJP, Schermer JJ, ter Meulen JJ. CVD diamond deposition on steel using arc-plated chromium nitride interlayers. Diamond and Related Materials. 2002;11(3-6):536-544.

12. Chao MJ, Wang WL, Liang EJ, Ouyang D. Microstructure and wear resistance of $\mathrm{TaC}$ reinforced Ni-based coating by laser cladding. Surface and Coatings Technology. 2008;202(10):19181922. 
13. Zhong M, Liu W, Yao K, Goussain JC, Mayer C, Becker A. Microstructural evolution in high power laser cladding of Stellite 6+WC layers. Surface and Coatings Technology. 2002;157(23):128-137.

14. Kim JH, Lee SK, Kwon OM, Hong SI, Lim DS. Thickness controlled and smooth polycrystalline CVD diamond film deposition on $\mathrm{SiO}_{2}$ with electrostatic self assembly seeding process. Diamond and Related Materials. 2009;18(10):12181222.

15. Campos RA, Contin A, Trava-Airoldi VJ, Moro JR, Barquete DM, Corat EJ. CVD diamond films growth on silicon nitride inserts $\left(\mathrm{Si}_{3} \mathrm{~N}_{4}\right)$ with high nucleation density by functionalization seeding. Materials Science Forum. 2012;727-728:1433-1438.

16. Campos RA, Trava-Airoldi VJ, Bagnato OR, Moro JR, Corat EJ. Development of nanocrystalline diamond windows for application in synchrotron beamlines. Vacuum. 2013;89:21-25.

17. Jackson MJ, Robinson GM, Ahmed W, Sein H, Jones NA, Ali $\mathrm{N}$, et al. Time-modulated chemical vapor deposition of diamond films. Journal of Materials Engineering and Performance. 2005;14(2):163-172.

18. Parikin, Killen PP, Rafterry A. Measurements of Residual Stresses in Cold-Rolled 304 Stainless Steel Plates Using X-Ray Diffraction With Rietveld. Atom Indonesia. 2009;35(1):19-36.

19. Zhang HW, Hei ZK, Liu G, Lu J, Lu K. Formation of nanostructured surface layer on AISI 304 stainless steel by means of surface mechanical attrition treatment. Acta Materialia. 2003;51(7):1871-1881
20. Kim SI, Yoo YC. Dynamic recrystallization behavior of AISI 304 stainless steel. Materials Science and Engineering: A. 2001;311(1-2):108-113.

21. Li YS, Tang Y, Yang Q, Xiao C, Hirose A. Growth and adhesion failure of diamond thin films deposited on stainless steel with ultra-thin dual metal interlayers. Applied Surface Science. 2010;256(24):7653-7657.

22. Dutta Majumdar J, Ramesh Chandra B, Nath AK, Manna I. Studies on compositionally graded silicon carbide dispersed composite surface on mild steel developed by laser surface cladding. Journal of Materials Processing Technology. 2008;203(103):505-512.

23. Butler JE, Sumant AV. The CVD of Nanodiamond Materials. Chemical Vapor Deposition. 2008;14(7-8):145-160.

24. Michler J, Mermoux M, von Kaenel Y, Haouni A, Lucazeau G, Blank E. Residual stress in diamond films: origins and modelling. Thin Solid Films. 1999;357(2):189-201.

25. Li YS, Hirose A. Direct coating of nanophase diamond films on steel substrate. Chemical Physics Letters. 2006;433(1-3):150153.

26. Campos RA, Contin A, Trava-Airoldi VJ, Barquete DM, Corat EJ. CVD of alternated MCD and NCD films on cemented carbide inserts. Journal of ASTM International. 2011;8(3):1-10.

27. Novikov NV, Dub SN. Hardness and fracture toughness of CVD diamond film. Diamond and Related Materials. 1996;5(9):10261030 . 